\title{
A Case of Increased Creatin Kinase Level Caused by Daptomycin
}

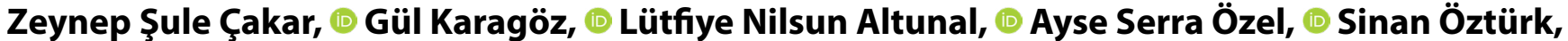 \\ Şenol Çomoğlu, (1) Mehmet Fatih Bektaşoğlu, (1) Fidan Doğan, AD Ayten Kadanalı
}

Department of Infectious Diseases, University of Health Sciences Turkey, Umraniye Training and Research Hospital, Istanbul, Turkey

\begin{abstract}
Daptomycin is a fermentation product produced by Streptomyces roseosporus, which can act on aerobic and anaerobic gram-positive bacteria in its cyclic form. Daptomycin has activity against methicillin-resistant Staphylococcus aureus (MRSA), glycopeptide-intermediate Staphylococcus aureus, coagulase-negative staphylococcus species, penicillin-resistant Streptococcus pneumoniae, enterococci, vancomycin-resistant bacteria such as Pediococcus, Leuconostoc and Lactobacillus, gram positive anaerobic bacteria including Clostridium difficile, Corynebacterium and Bacillus bacteria and peptostreptococci. The primary toxicity associated with daptomycin is myopathy, which is rare. Muscle pain, muscle weakness and increased creatine kinase (CK) levels (MM isoenzyme) are detected due to myopathy. Paresthesia and reversible paralysis can be observed infrequently. In this article, a case of daptomycin-associated creatine phosphokinase elevation is presented. Clinical signs and symptoms improved with normal CK levels after discontinuation of daptomycin. Myopathy should be kept in mind in case of sudden muscle pain and high CK levels during the treatment with daptomycin.

Keywords: Daptomycin; myopathy; creatine kinase.
\end{abstract}

$\mathrm{D}$ aptomycin is a broad-spectrum antibiotic that is obtained as a by-product of Streptomyces roseosporus fermentation, which can act on aerobic and anaerobic gram-positive bacteria in its cyclic form. Daptomycin has been reported to show activity against methicillin-resistant Staphylococcus aureus (MRSA), glycopeptide-intermediate Staphylococcus aureus, coagulase-negative staphylococcus species, penicillin-resistant Streptococcus pneumoniae, enterococci, vancomycin-resistant bacteria such as Pediococcus, Leuconostoc and Lactobacillus, gram positive anaerobic bacteria including Clostridium difficile, Corynebacterium and Bacillus bacteria and peptostreptococci [1]. Daptomycin has a rapid (1-4 hours) dose-dependent bactericidal action against these bacteria ${ }^{[2,3]}$. Its half-life is about 8 hours and it has a post-antibiotic effect lasting for 6-10 hours. Therefore, it provides advantage with the use of a single daily dose. Although the recommended daily dose is $4-6 \mathrm{mg} / \mathrm{kg}$, the dose can be increased up to $8-10 \mathrm{mg} / \mathrm{kg}$ in severe infections. Its major route of elimination is renal excretion. In patients with creatinine clearance below 30 $\mathrm{ml} / \mathrm{min}$, the dose should be adjusted and the drug should be administered at $4 \mathrm{mg} / \mathrm{kg}$ doses every 48 hours. Daptomycin penetration into deep tissues is good and has been found to be more effective against MRSA in biofilm than other antibiotics. It has FDA approval for the treatment of complicated skin and soft tissue infections, right-sided infective endocarditis caused by methicillin-sensitive and -resistant S. aureus and in S.aureus bacteremia. In the

Correspondence (İletişim): Gül Karagöz, M.D. Saglik Bilimleri Universitesi Umraniye Egitim ve Arastirma Hastanesi,

Enfeksiyon Hastaliklari Servisi Istanbul, Turkey

Phone (Telefon): +90 5057512688 E-mail (E-posta): gulkaragozmd@yahoo.com

Submitted Date (Başvuru Tarihi): 30.06.2018 Accepted Date (Kabul Tarihi): 28.12.2018

Copyright 2020 Haydarpaşa Numune Medical Journal

OPEN ACCESS This is an open access article under the CC BY-NC license (http://creativecommons.org/licenses/by-nc/4.0/) 
guidelines published by IDSA and prepared for the treatment of MRSA-related infections in 2011, it has taken its place among the first options in the empirical treatment of complicated skin and soft tissue infections such as deep soft tissue infections, abscess, cellulitis, surgical/traumatic wound infections, burns and infected ulcers and bonejoint infections. Although the most frequently reported side effects of daptomycin are gastrointestinal side effects, the most remarkable side effect is myopathies ${ }^{[4,5]}$. In this article, we aimed to present a patient who was followed up with the diagnosis of spondylodiscitis and developed widespread muscle pain in the lower and upper extremities and increased CK during daptomycin treatment, whose symptoms and CK values regressed to normal limits after discontinuation of the drug.

\section{Case Report}

Spondylodiscitis was detected in the lumbar spine magnetic resonance imaging (MRI) of a 52-year-old female patient who admitted with high fever and low back pain, and a disc biopsy was performed by hospitalizing the patient. Daptomycin 1x500 mg intravenous (IV) treatment was initiated empirically after biopsy due its rapid bactericidal effect, to the patient who had a four-time lumbar disc herniation operation history. Creatine kinase (CK) level was $17 \mathrm{U} / \mathrm{L}$ in the biochemical tests requested before the daptomycin treatment was initiated (CK: 29-168 U/L). In the patient whose biopsy material showed methicillin sensitive staphylococcus aureus (MSSA) growth, CK level was $21 \mathrm{U} / \mathrm{L}$ on day 4 of current treatment. Severe muscle pain developed in the lower and upper extremities on the $11^{\text {th }}$ day of hospitalization. When the CK level was detected as 2940 U/L, daptomycin was discontinued and ampicillin-sulbactam $4 \times 1.5$ g IV treatment was started. Two days later, the control CK level was found to be $6358 \mathrm{U} / \mathrm{L}$. Parenteral fluid treatment was arranged after consultation with internal medicine and nephrology. Daily CK level and kidney function tests were followed up. One week after drug discontinuation, CK level was reduced to normal values (109 U/L). The patient was discharged after completing the ampicillin-sulbactam parenteral treatment in 4 weeks, and oral therapy for the next 3 more months was planned.

\section{Discussion}

The most common side effects related to daptomycin treatment are gastrointestinal system side effects such as nausea-vomiting, decreased appetite, diarrhea and constipation. In addition, creatine phosphokinase (CK) increase, weakness, muscle pain, injection site pain, headache, anemia, hypopotassemia, renal impairment, peripheral edema, arthralgia, and rarely eosinophilic pneumonia side effects can also be seen ${ }^{[4-6]}$. In our case, in the second week of daptomycin use, widespread muscle pain in the lower and upper extremities and increased CK levels developed. Although rare, the primary toxicity of daptomycin is myopathy and often manifests itself as muscle pain and muscle weakness. The frequency of paraesthesia and reversible paralysis is low. Increased CK levels can be seen from laboratory parameters. In case of use of hydroxy-methyl-glutaryl reductase (HMG-CoA) enzyme inhibitors together with daptomycin, an increase in muscle toxicity side effect is observed if the patient has a severe disease or renal failure. Considering drug interactions, it does not show in vitro antagonistic effects with other antibiotics. It requires careful monitoring for muscle toxicity when used with statins ${ }^{[1,7,8]}$. In our case, there was no history of drug use other than daptomycin that could cause increased CK levels. In a study by Berg et al., 498 patients using daptomycin were evaluated in terms of high CK levels. Patients were divided into three groups: those who used daptomycin alone, those who received statin therapy concomitant with daptomycin, and those who discontinued their statin therapy during daptomycin use. These three groups were followed for 7-14 days and the CK elevation in the patients was between $5.1 \%$ and $12 \%$; there was no significant difference between the groups. For this reason, patients receiving daptomycin treatment are recommended to continue their treatment with statin therapy under CK monitoring, due to the risk of high CK levels ${ }^{[9]}$. It is recommended that patients using daptomycin should have their CK levels checked once a week in terms of myopathy risk. If unexplained myopathy findings develop in patients during treatment for any reason and the CK level is above $1000 \mathrm{U} / \mathrm{L}$, or if the CK level rises to $\geq 5-10$ times the upper limit without symptoms, the drug should be discontinued [7]. In our case, the drug was discontinued when CK level was detected as $2940 \mathrm{U} / \mathrm{L}$ on the $11^{\text {th }}$ day of daptomycin treatment $(4 \mathrm{mg} / \mathrm{kg})$ and accompanying myopathy symptoms existed. When the literature iss reviewed, the increase in CK enzyme level was found to be $2.1 \%$ in patients using daptomycin and $1.4 \%$ in the control group. In $0.4 \%$ of the patients, the drug was discontinued due to this side effect, and clinical symptoms and increased CK levels rapidly improved. In the same study, CK increased in $6.7 \%$ of the patients with the use of high dose $(6 \mathrm{mg} / \mathrm{kg})$ daptomycin, and therefore drug treatment was discontinued in $2.5 \%$ of the patients ${ }^{[5]}$. In our case, the clinical and laboratory findings of the patient improved after drug discontinuation. In a study conducted by Figueroa et al., High dose ( $>8 \mathrm{mg} /$ 
$\mathrm{kg}$ ) daptomycin treatment was given, CK level was found to be elevated in three of 61 patients, and laboratory values of the patients improved with the discontinuation of the drug ${ }^{[5]}$. When the literature is reviewed, in phase 3 studies conducted on daptomycin, the side effect of myopathy is observed to develop between the $7^{\text {th }}$ and $12^{\text {th }}$ days of the treatment and all these side effects were seen to improve with the discontinuation of the drug ${ }^{[4]}$. In a study conducted in healthy volunteers by giving high dose $(8 \mathrm{mg} / \mathrm{kg})$ daptomycin for 14 days, none of the volunteers developed CK elevation. All these results reveal the need for weekly controls of muscle enzymes in patients during treatment follow-up, regardless of the drug dose used ${ }^{[5]}$.

\section{Conclusion}

In patients receiving daptomycin therapy, drug-induced increased CK levels and myopathy may be observed. Weekly CK monitoring is recommended. Treatment should be discontinued if the CK levels are 5 times higher than normal CK levels and accompanying symptoms exist, or the CK levels are 10 times higher in asymptomatic patients. With the cessation of treatment, symptoms improve in a short time.

Informed Consent: Approval was obtained from the patient. Peer-review: Externally peer-reviewed.

Conflict of Interest: None declared.

Authorship Contributions: Concept: S.E.C., G.K.; Design: A.K.; Data Collection or Processing: S.C., M.F.B., F.D.; Analysis or Interpretation: S.E.C., A.K., G.K.; Literature Search: L.N.A., S.O., A.S.O.; Writing: S.E.C., G.K.
Financial Disclosure: The authors declared that this study received no financial support.

\section{References}

1. Kosmidis C, Levine DP. Daptomycin: pharmacology and clinical use. Expert Opin Pharmacother 2010;11:615-25. [CrossRef]

2. Pankey GA, Sabath LD. Clinical relevance of bacteriostatic versus bactericidal mechanisms of action in the treatment of Gram-positive bacterial infections. Clin Infect Dis 2004;38:864-70. [CrossRef]

3. Finberg RW, Moellering RC, Tally FP, Craig WA, Pankey GA, Dellinger EP, et al. The importance of bactericidal drugs: future directions in infectious disease. Clin Infect Dis 2004;39:131420. [CrossRef]

4. Bozkurt GY, Kutlu H, Arslan A, Memikoğlu O. Yeni Bir Antibakteriyel Ajan: Daptomisin. Ankara Üniversitesi Tıp Fakültesi Mecmuası 2010;63:085-8. [CrossRef]

5. Ergüt Sezer B, Arman D. Deri ve Yumuşak Doku İnfeksiyonlarında Daptomisin Kullanımı. Yoğun Bakım Dergisi 2012;10:18. [CrossRef]

6. Kömür S, Ulu A, Kurtaran B, İnal AS, Kuşçu F, Tekin D, Taşova Y. Sudden respiratory failure and eosinophilic pneumonia in patients treated with daptomycin: a report of five cases. Cukurova Med J 2016;41:396-99. [CrossRef]

7. Sauermann R, Rothenburger M, Graninger W, Joukhadar C. Daptomycin: a review 4 years after first approval. Pharmacology 2008;81:79-91. [CrossRef]

8. Özaras R, Tabak F. Daptomisin. Klimik Dergisi 2010;23:35-8.

9. Berg ML, Estes LL, Dierkhising RA, Curran B, Enzler MJ. Evaluation of impact of statin use on development of CPK elevation during daptomycin therapy. Ann Pharmacother 2014;48:3207. [CrossRef] 